\title{
Radiation Exposure to the Nuclear Medicine Personnel During Preparation and Handling of ${ }^{213}$ Bi-Radiopharmaceuticals
}

\author{
Parul Thakral ${ }^{1}$, Ishita Sen ${ }^{1}$, Jakub Simecek ${ }^{2}$, Sebastian Marx², Jyotsna Kumari ${ }^{1}$, Sunil Kumar ${ }^{1}$, Pankaj Tandon ${ }^{3}$, \\ Sugandha Dureja ${ }^{1}$, and Vineet Pant ${ }^{1}$ \\ ${ }^{1}$ Department of Nuclear Medicine, Fortis Memorial Research Institute, Gurgaon, India; ${ }^{2}$ Research and Development, Isotope \\ Technologies Garching GmbH, Bavaria, Germany; and ${ }^{3}$ Radiological Safety Division, Atomic Energy Regulatory Board, \\ Mumbai, India
}

\begin{abstract}
Because of the excellent ability of a-particles to transfer a high amount of energy over a short tissue range, targeted a-therapy has been attracting rising numbers of nuclear medicine centers. In this study, we estimated the radiation exposure to the occupational workers with pocket dosimeters during handling of the a-emitter ${ }^{213} \mathrm{Bi}$, used for targeted a-therapy of neuroendocrine tumor and castration-resistant prostate cancer patients. The dose rates from patients at different distances and time points after injection of the therapy were also evaluated. Methods: This prospective study was done in the Department of Nuclear Medicine at Fortis Memorial Research Institute, Gurgaon, India. Twelve patients with neuroendocrine tumors or castration-resistant prostate cancer were enrolled to receive ${ }^{213} \mathrm{Bi}-\mathrm{DOTATOC}$ or ${ }^{213} \mathrm{Bi}$-prostate-specific membrane antigen therapy, respectively. Each patient received 2-3 intravenous injections of ${ }^{213} \mathrm{Bi}-$ peptide, 266-362 MBq (7.2-9.8 mCi) in a single cycle over 2-3 d. The radiation exposure to nuclear medicine personnel at the chest and extremity levels was assessed for tasks such as elution, dispensing, injecting, and collecting blood samples. Radiation levels were measured at distances of $1 \mathrm{~cm}$ and $1 \mathrm{~m}$ from patients immediately after, and at 1,2 , and $4 \mathrm{~h}$ after, the administration of ${ }^{213} \mathrm{Bi}$-peptide. Results: The external dose incurred at the chest level by radiopharmacists during synthesis, by physicians during injection, by technologists during imaging, and by nurses during sample collection was $2-7 \mu \mathrm{Sv} /$ procedure. The extremity dose was 1-14 $\mu \mathrm{Sv} /$ procedure. The dose rate at $1 \mathrm{~m}$ from patients immediately after ${ }^{213} \mathrm{Bi}$-radiopharmaceutical injection was $0.02-0.03 \mu \mathrm{Sv} / \mathrm{MBq} \cdot h$. Conclusion: The external radiation doses received by occupational workers involved in various procedures were far below the limit prescribed by the regulatory authority $(20 \mathrm{mSv} / \mathrm{y})$.
\end{abstract}

Key Words: a-therapy; ${ }^{213} \mathrm{Bi}$; targeted therapy; radiation safety; personnel monitoring; TAT

J Nucl Med Technol 2020; 48:68-72

DOI: $10.2967 /$ jnmt.119.230516

\footnotetext{
Received May 2, 2019; revision accepted Jul. 6, 2019.

For correspondence or reprints contact: Ishita Sen, Department of Nuclear Medicine, Fortis Memorial Research Institute, Gurgaon, Haryana 122002, India.

E-mail: ibaratsen@gmail.com

Published online Oct. 11, 2019.

COPYRIGHT @ 2020 by the Society of Nuclear Medicine and Molecular Imaging.
}

$\mathbf{T}$ he main objective of targeted radionuclide therapy is the ability to selectively deliver cytotoxic radiation to cancer cells while minimizing toxicity to surrounding healthy tissues. To date, $\beta$-emitting radioisotopes $\left({ }^{131} \mathrm{I},{ }^{177} \mathrm{Lu},{ }^{188} \mathrm{Re}\right)$ have been used to treat various types of cancer, such as neuroendocrine tumors, castration-resistant prostate cancer, and thyroid cancer. Compared with the somewhat lower linearenergy-transfer $\beta$-particle emitters, which cause predominantly single-strand DNA damage, $\alpha$-particles, with high linear-energy transfer, lead more frequently to double-strand DNA damage and, therefore, more effective cancer cell death. A single $\alpha$-particle is sufficient to destroy the cell nucleus, whereas $\beta$-particles need many more hits at the level of the cell nucleus (1). The radionuclide ${ }^{213} \mathrm{Bi}$ is a mixed $\alpha / \beta$-emitter with a half-life of $46 \mathrm{~min}$ (2) and decays mainly via $\beta$-emission to the pure $\alpha$-emitter ${ }^{213}$ Po (half-life, $4.2 \mu \mathrm{s}$; $\alpha$-energy, 8.375 $\mathrm{MeV})$. The remaining $2.2 \%$ of ${ }^{213} \mathrm{Bi}$ decays lead to ${ }^{209} \mathrm{Tl}$ via $\alpha$-particle emission $(\mathrm{E} \alpha=5.549 \mathrm{MeV}, 0.16 \%, \mathrm{E} \alpha=5.869$ $\mathrm{MeV}, 2.01 \%$ ). Both ${ }^{213} \mathrm{Po}$ and ${ }^{209} \mathrm{Tl}$ finally decay via ${ }^{209} \mathrm{~Pb}$ (half-life, $3.25 \mathrm{~h}$; $\beta$-decay) into stable ${ }^{209} \mathrm{Bi}$ (3). Because of the considerably short half-life of ${ }^{213} \mathrm{Bi}$, it can deliver a high radiation dose rate to the target within a very short period (4). Most of the total particle energy emitted in each disintegration of ${ }^{213} \mathrm{Bi}$ originates from $\alpha$-decay $(92.7 \%)$; the rest is contributed by $\beta$-particle emission, including the decay of ${ }^{209} \mathrm{~Pb}(5)$. The decay of ${ }^{213} \mathrm{Bi}$ is also accompanied by emission of a $440-\mathrm{keV}$ photon (emission probability, 26.1\%), which can be detected using $\gamma$-cameras equipped with commercially available high-energy collimators, thus allowing the ${ }^{213} \mathrm{Bi}$ biodistribution to be monitored and pharmacokinetic and dosimetric studies to be performed (6). These physical characteristics, together with convenient availability from a ${ }^{225} \mathrm{Ac} /{ }^{213} \mathrm{Bi}$ generator and feasible labeling techniques, can make ${ }^{213} \mathrm{Bi}$ one of the most commonly used $\alpha$-emitters for medical applications. In our study, ${ }^{213} \mathrm{Bi}$-labeled DOTATOC and prostate-specific membrane antigen (PSMA) were used in patients with neuroendocrine tumors and castration-resistant prostate cancer, respectively.

Personnel monitoring is an integral part of any radiation safety program. It aims to keep the occupational radiation 
exposure as low as reasonably achievable, ensuring that the benefits of radiation exposure outweigh any resulting detriment (7). In nuclear medicine, the radiation exposure of personnel deserves particular consideration, especially in view of the regular long-term exposure such workers receive. The personnel are likely to be exposed during radiopharmaceutical synthesis, radiopharmaceutical administration, or scan acquisition. The radiation levels from the patient and the waste generated from handling of the radioactive source pose an environmental detriment. Radiation safety issues regarding $\alpha$-emitters have not yet been discussed to a relevant extent, probably because of the limited availability of $\alpha$-particle emitters and the relatively few studies involving these novel treatments. Because decay of ${ }^{213} \mathrm{Bi}$ results in emission of $\alpha$-particles, $\beta$-particles, and $\gamma$-rays, it becomes imperative to study the radiation exposure of the personnel who use ${ }^{213} \mathrm{Bi}$-radiopharmaceuticals. Therefore, the present study was performed to estimate the radiation exposure of workers who handle ${ }^{213} \mathrm{Bi}$-radiopharmaceuticals for targeted $\alpha$-therapy of neuroendocrine tumor and prostate cancer patients.

\section{MATERIALS AND METHODS}

\section{Patients}

Twelve patients with neuroendocrine tumors $(n=7)$ or castration-resistant prostate cancer $(n=5)$ were enrolled for ${ }^{213} \mathrm{Bi}$ DOTATOC or ${ }^{213} \mathrm{Bi}-\mathrm{PSMA}$ therapy, respectively, in the Nuclear Medicine Department of Fortis Memorial Research Institute, Gurgaon, India. The Institutional Ethics Committee approved the study. The mean age of the patients was $51.25 \mathrm{y}$ (range, 24-67 y). They were treated with 2-3 injections of ${ }^{213}$ Bi-PSMA-617 or DOTATOC (266$362 \mathrm{MBq}$ [7.2-9.8 mCi]), respectively, per cycle, with a cumulative average injected activity of $804.75 \mathrm{MBq}(21.75 \mathrm{mCi})$. A single intraarterial infusion for liver lesions was also done in 3 patients.

\section{Generator and Chemicals}

A $370-\mathrm{MBq}(10-\mathrm{mCi}){ }^{225} \mathrm{Ac} /{ }^{213} \mathrm{Bi}$ generator was procured from ITG and eluted every $2-3 \mathrm{~h}$ during its shelf life (36 elutions in total), with the typical frequency being 6 elutions per day at a 2- to 3 -h interval. The generator yielded a total of $11 \mathrm{GBq}(303.21 \mathrm{mCi})$ of ${ }^{213} \mathrm{Bi}$ with an average activity of $316 \mathrm{MBq}(8.54 \mathrm{mCi})$ in 36 elutions. DOTATOC and PSMA-617 of good-manufacturing-practice grade were obtained from ABX. ${ }^{213}$ Bi-PSMA-617 and DOTATOC were prepared by mixing the generator eluate (containing $\mathrm{BiI}^{4-}$ and $\mathrm{BiI}_{5}{ }^{2-}$ complexes) directly in a vial containing $0.5 \mathrm{M}$ sodium acetate buffer (aq) and $150 \mu \mathrm{g}$ of the precursor. The reaction mixture was heated at $90^{\circ} \mathrm{C}$ for 10 min using a heating block.

Radiochemical purity was determined by instant thin-layer chromatography, silica gel (Varian), as a stationary phase and sodium citrate $(0.1 \mathrm{M}, \mathrm{pH} 5)$ as a mobile phase. The final formulation was sterile-filtered (Millex-GV, $0.22 \mu \mathrm{m}$; Millipore) before being administered to the patient. The fast handling of the elution, labeling, and quality control procedures allowed for completion of the procedure and release within a maximum of $40 \mathrm{~min}$.

\section{Dosimeter and Readout System}

Calibrated electronic pocket dosimeters (MyDose MINI-pdm, G-9679) with solid-state detectors were used to measure the whole-body and extremity doses. The measurement range of the detectors was $0.1-100 \mu \mathrm{Sv}$, and both accumulated dose and dose rate were displayed. These dosimeters have silicon semiconductor detectors with an accuracy and linearity within $\pm 10 \%$. They were worn at the level of the chest and the dorsal surface of hands at the same position for each measurement of doses. Each worker was provided with 1 electronic pocket dosimeter throughout the given task. The whole-body and extremity doses received by the worker were read directly from the dosimeter and recorded at the end of the task. The instantaneous dose rate readings from patients and the background radiation levels in the controlled and uncontrolled areas were measured using a RAM ION meter (Rotem Industries), which is a calibrated, battery-operated, portable ion-chamber survey meter with a range of $0.1-500 \mathrm{mSv} / \mathrm{h}$.

\section{Exposed Personnel}

Radiopharmacists, physicians, technologists, and nurses were the critical group of workers potentially exposed to ionizing radiation while performing tasks associated with ${ }^{213} \mathrm{Bi}$-radiopharmaceuticals. Radiopharmacists performed 4 steps in the preparation of the ${ }^{213} \mathrm{Bi}$ radiopharmaceutical: elution of the ${ }^{213} \mathrm{Bi}$, synthesis of the radiopharmaceutical, quality control, and dose dispensing. The total amount of radioactivity handled during labeling and throughout each procedure was recorded.

The ${ }^{213} \mathrm{Bi}$-radiopharmaceuticals were transported from the hot laboratory to the injection room by the attendant. The activity was administered by the authorized user (nuclear medicine physicians, technologists). Before the injection, patients were prepared with an intravenous cannula, and patency was checked by flushing with saline. The activity was administered as a slow injection and was followed by flushing with saline to allow all the activity to be delivered into the vein. The total activity administered and the time spent were recorded. The technologists performed the imaging procedure. This included positioning the patient, acquiring the images, and helping the patient for the duration of the study. While the $\gamma$-camera was being operated, the technologist sat at a distance from it and monitored the patient. The total dose received by the technologist was measured from the time the patient was escorted to the bathroom (to void the bladder) until the time the patient was released to the waiting area. A planar whole-body scan was acquired with a $\gamma$-camera (Philips Brightview) using a high-energy all-purpose collimator at a bed speed of $6 \mathrm{~cm} / \mathrm{h}$ with the $20 \%$ energy windows peaked at $440 \mathrm{keV}$. The scans were acquired immediately after the injection and at 2 and $3 \mathrm{~h}$. To assess plasma clearance, trained nurses collected blood samples immediately after injection and at $10 \mathrm{~min}, 20 \mathrm{~min}, 30 \mathrm{~min}, 40 \mathrm{~min}, 50 \mathrm{~min}, 1 \mathrm{~h}$, and $2 \mathrm{~h}$. To assess renal clearance, the attending staff collected urine samples $(1 \mathrm{~mL})$ immediately after the injection and at 1 and $2 \mathrm{~h}$. The patients remained in an isolation ward but under clinical supervision for up to 4-6 h after injection, during which they were monitored for any adverse effects. Dose rates emanating from these patients were measured using the RAM ION meter for each administration at a $1-\mathrm{cm}$ and $1-\mathrm{m}$ distance from the anterior chest of each patient, immediately after the administration and at 1,2 , and $4 \mathrm{~h}$.

\section{RESULTS}

\section{Dose to Radiopharmacists}

The radiopharmacists performed the whole procedure of elution, synthesis, quality control testing, and dose dispensing behind an L-shield while following the 3 cardinal principles of radiation safety: time, distance, and shielding. The 
TABLE 1

Whole-Body and Extremity Radiation Dose to Radiopharmacist

\begin{tabular}{|c|c|c|c|c|c|c|}
\hline \multirow[b]{2}{*}{ Radiopharmacist } & \multirow{2}{*}{$\begin{array}{c}\text { Handled } \\
\text { activity (MBq) }\end{array}$} & \multirow[b]{2}{*}{ Procedures $(n)$} & \multirow{2}{*}{$\begin{array}{c}\text { Time per } \\
\text { procedure (min) }\end{array}$} & \multirow{2}{*}{$\begin{array}{c}\text { Dose per } \\
\text { procedure }(\mu \mathrm{Sv})\end{array}$} & \multicolumn{2}{|c|}{$\begin{array}{c}\text { Extremity dose per } \\
\text { procedure }(\mu \mathrm{Sv})\end{array}$} \\
\hline & & & & & Right hand & Left hand \\
\hline 1 & $323 \pm 45$ & 18 & $34.31 \pm 2.21$ & $4.47 \pm 1.6$ & $11.46 \pm 2.63$ & $7.30 \pm 2.40$ \\
\hline 2 & $341 \pm 21$ & 7 & $36.64 \pm 2.54$ & $6.24 \pm 1.8$ & $12.50 \pm 2.53$ & $9.20 \pm 1.41$ \\
\hline 3 & $284 \pm 40$ & 11 & $35.46 \pm 2.32$ & $5.56 \pm 1.4$ & $11.20 \pm 2.70$ & $8.80 \pm 1.57$ \\
\hline
\end{tabular}

Data are mean \pm SD.

doses incurred by 3 radiopharmacists at the level of the chest during the whole procedure are shown in Table 1 . They received a mean whole-body radiation dose of $5.42 \mu \mathrm{Sv}$ per procedure when an average activity of $316 \mathrm{MBq}(8.54 \mathrm{mCi})$ was handled for an average time of $35 \mathrm{~min}$. The mean extremity dose received by the 3 radiopharmacists was 11.88 $\mu \mathrm{Sv} /$ procedure for the right hand and $8.43 \mu \mathrm{Sv} /$ procedure for the left hand when an average activity of $316 \mathrm{MBq}(8.54$ $\mathrm{mCi}$ ) was handled (Table 1). The right hand received a slightly higher dose because all 3 radiopharmacists were right-handed.

\section{Dose to Injectors}

The radiation dose received by the injecting physicians and technologists at the level of the chest and hands, when an average of $288 \mathrm{MBq}(7.8 \mathrm{mCi})$ was injected, is shown in Table 2 . The mean whole-body external radiation dose was $0.33 \mu \mathrm{Sv} /$ procedure, and the mean extremity dose was 1.45 $\mu \mathrm{Sv} /$ procedure to the right hand and $0.79 \mu \mathrm{Sv} /$ procedure to the left hand.

\section{Dose to Technologists}

The average time spent by the technologists in handling the patients and acquiring a whole-body scan was $56 \mathrm{~min}$, and the mean external whole-body radiation dose received was $2.3 \mu \mathrm{Sv}$ /procedure (Table 3 ).

\section{Dose to Nurses}

The extremity dose received by the nurses during blood sample collection for a single patient was in the range of 5-7 $\mu \mathrm{Sv}$ for the right hand and 3-5 $\mu \mathrm{Sv}$ for the left hand
(Table 4). This dose was incurred in the collection of 7 samples $(1 \mathrm{~mL}$ each), with the average time to collect 1 sample being 3-4 min (Table 4).

\section{Dose Rates from Patients}

The instantaneous dose rates measured at chest level at various distances from the patients immediately after administration of the therapy, and 1,2 , and $3 \mathrm{~h}$ afterward, are shown in Table 5 . Net measured values were obtained by subtracting the background dose rate (i.e., background dose rate measured in nuclear medicine injection area) from the gross measured values. The maximum net measured dose rate immediately after administration of the therapy was $115 \mu \mathrm{Sv} / \mathrm{h}$ at $1 \mathrm{~cm}$ and $7.67 \mu \mathrm{Sv} / \mathrm{h}$ at $1 \mathrm{~m}$. The dose rates at $1 \mathrm{~m}, 4 \mathrm{~h}$ after injection, were equivalent to mean background values in an uncontrolled area $(0.22 \mu \mathrm{Sv} / \mathrm{h})$.

\section{DISCUSSION}

A 2014 study demonstrated that targeted $\alpha$-therapy with ${ }^{213} \mathrm{Bi}$-DOTATOC has potential to break radioresistance against $\beta$-emitters ( 6 ) Although several studies are ongoing with targeted $\alpha$-therapy, there is a paucity of literature on personnel monitoring. To the best of our knowledge, our hospital was the first in India to procure a ${ }^{225} \mathrm{Ac} / 213 \mathrm{Bi}$ generator. According to the 2007 recommendations of the International Commission on Radiological Protection (8), the effective radiation dose to personnel should not exceed 20 $\mathrm{mSv} / \mathrm{y}$ averaged over $5 \mathrm{y}$ or $50 \mathrm{mSv}$ in any year $(8)$. Because targeted $\alpha$-therapy is a novel therapy, the aim of this

TABLE 2

Whole-Body External and Extremity Dose to Injector

\begin{tabular}{|c|c|c|c|c|c|c|}
\hline \multirow[b]{2}{*}{ Radiation worker } & \multirow{2}{*}{$\begin{array}{c}\text { Injected } \\
\text { activity (MBq) }\end{array}$} & \multirow[b]{2}{*}{ Injections $(n)$} & \multirow{2}{*}{$\begin{array}{c}\text { Time per } \\
\text { injection (min) }\end{array}$} & \multirow{2}{*}{$\begin{array}{c}\text { Dose per } \\
\text { injection }(\mu \mathrm{Sv})\end{array}$} & \multicolumn{2}{|c|}{ Extremity dose per injection $(\mu \mathrm{Sv})$} \\
\hline & & & & & Right hand & Left hand \\
\hline Physician 1 & $268 \pm 42$ & 7 & $2.66 \pm 0.97$ & $0.43 \pm 0.53$ & $1.00 \pm 0.81$ & $0.72 \pm 0.75$ \\
\hline Physician 2 & $250 \pm 60$ & 6 & $4.22 \pm 0.89$ & $0.33 \pm 0.52$ & $1.75 \pm 0.52$ & $0.50 \pm 0.55$ \\
\hline Physician 3 & $235 \pm 53$ & 7 & $3.12 \pm 1.02$ & $0.33 \pm 0.52$ & $1.33 \pm 0.52$ & $1.10 \pm 0.63$ \\
\hline Technologist 1 & $260 \pm 33$ & 6 & $4.02 \pm 0.99$ & $0.26 \pm 0.41$ & $1.50 \pm 0.54$ & $0.67 \pm 0.52$ \\
\hline Technologist 2 & $323 \pm 32$ & 5 & $2.45 \pm 0.89$ & $0.40 \pm 0.55$ & $1.52 \pm 0.54$ & $1.00 \pm 0.71$ \\
\hline Technologist 3 & $276 \pm 28$ & 5 & $3.48 \pm 1.05$ & $0.25 \pm 0.50$ & $1.65 \pm 0.96$ & $0.75 \pm 0.5$ \\
\hline
\end{tabular}

Data are mean \pm SD. 
TABLE 3

Dose to Technologist During Scanning

\begin{tabular}{lccccc}
\hline Technologist & Injected activity $(\mathrm{MBq})$ & Patients handled $(n)$ & Total scans $(n)$ & Time per scan $(\min )$ & $\begin{array}{c}\text { Whole-body dose } \\
\text { per scan }(\mu \mathrm{Sv})\end{array}$ \\
\hline 1 & $287 \pm 42$ & 8 & 24 & $55.23 \pm 2.96$ & $2.45 \pm 1.01$ \\
2 & $291 \pm 50$ & 4 & 12 & $57.45 \pm 1.98$ & $2.23 \pm 0.98$ \\
& & & & & \\
\hline Data are mean \pm SD. & & & & \\
\hline
\end{tabular}

work was to monitor the exposure of radiation workers to ${ }^{213} \mathrm{Bi}$-radiopharmaceuticals. An initial study evaluated the radiation safety aspects of intravenous doses of ${ }^{223} \mathrm{Ra}$ dichloride (Xofigo; Bayer) in patients with castration-resistant prostate cancer and skeletal metastases (9). The authors documented that the dose rates from patients administered ${ }^{223}$ Ra-dichloride (half-life, $11.43 \mathrm{~d}$; average $\alpha$-energy, $5.78 \mathrm{MeV}$ ) was less than $2 \mu \mathrm{Sv} / \mathrm{MBq} \cdot \mathrm{h}$ on contact and averaged $0.02 \mu \mathrm{Sv} / \mathrm{MBq} \cdot \mathrm{h}$ at $1 \mathrm{~m}$ immediately after administration. These rates were less than the conservative theoretic exposure rate constant for an unshielded point source of ${ }^{223} \mathrm{Ra}$ in equilibrium with progeny $(\sim 0.05 \mu \mathrm{Sv} / \mathrm{MBq} \cdot \mathrm{h})$ and were well within the regulatory guidelines for the release of patients after administration. Dose rates measured from patients at various times and distances after injection were a guide to whether the dischargeable limits were exceeded and whether isolation was required after $\alpha$-therapy. According to our measurements, the calculated dose rate per injected activity was $0.02-0.03 \mu \mathrm{Sv} / \mathrm{MBq} \cdot \mathrm{h}$ at $1 \mathrm{~m}$ immediately after therapy. This result is also less than the conservative theoretic exposure rate constant for an unshielded point source of ${ }^{213} \mathrm{Bi}(\sim 0.19 \mu \mathrm{Sv} / \mathrm{MBq} \cdot \mathrm{h})(10)$. The 1-m dose rates at $4 \mathrm{~h}$ after injection dropped to mean background values $(0.22 \mu \mathrm{Sv} / \mathrm{h})$. Accordingly, the patients need not be kept in isolation but can instead be monitored for up to $4 \mathrm{~h}$ after the treatment. They can then be discharged after receiving written and verbal instructions on the precautions to be taken with regard to blood, urine, and stool for the following week.

Because no other studies on ${ }^{213} \mathrm{Bi}$ are available, we could not directly compare our results with previous results. Comparison of studies performed with different radionuclides is made difficult by the varying energies of the particulates, as well as the varying $\gamma$-emissions, half-lives, and work practices. However, our estimated values for whole-body exposure of radiation workers to ${ }^{213} \mathrm{Bi}$ were either comparable to or less with those published in the literature for other radionuclides, such as ${ }^{88 \mathrm{~m}} \mathrm{Tc}(11),{ }^{68} \mathrm{Ga}(12),{ }^{18} \mathrm{~F}(13,14)$, ${ }^{188} \mathrm{Re}(15),{ }^{223} \mathrm{Ra}(9)$, and ${ }^{177} \mathrm{Lu}$ (16). The whole-body effective dose received by radiopharmacists during synthesis, by physicians during injection, and by technologists during imaging was in the range of 2-7 $\mu \mathrm{Sv}$ /procedure, which allows approximately 2,000 such procedures to be performed per year before reaching the regulatory-authority-stipulated annual limit of $20 \mathrm{mSv}$ averaged over $5 \mathrm{y}$ (8). Thus, assuming the use of a $370-\mathrm{MBq}(10-\mathrm{mCi}){ }^{213} \mathrm{Bi}$ generator every month, resulting in 40 elutions for every generator, we could potentially perform 480 procedures per year-far fewer (25\%) than the number it would take to reach the allowed limit. In the current study, doses to the extremities of a radiation worker during synthesis, injection, and sample collection ranged from 1 to $13 \mu \mathrm{Sv} /$ procedure. If the same radiation worker were to continue to work for a whole year, the worker could perform over 3,300 procedures before reaching the threshold for the extremities $(50 \mathrm{mSv}$; i.e., one tenth of the annual extremity dose limit of $500 \mathrm{mSv}$ ). In the study with ${ }^{223} \mathrm{RaCl}_{3}$, the authors estimated that a worker might receive approximately $41 \mu \mathrm{Sv}$ to the extremities for each 3.5-MBq administration of ${ }^{223} \mathrm{RaCl}_{3}$ (9).

The readings from the chest and wrist thermoluminescent dosimeter badges were 0.5 and $0.6 \mathrm{mSv}$, respectively, for workers engaged in both cumulative ${ }^{213} \mathrm{Bi} \alpha$-therapy and routine departmental work during the 3-mo monitoring period. These doses were well within permissible limits and were not significantly higher than the doses received by workers who performed routine departmental work alone.

TABLE 4

Extremity Dose to Nurse During Blood Sampling

\begin{tabular}{lccccc}
\hline & & & & \multicolumn{2}{c}{ Extremity dose per patient $(\mu S v)$} \\
\cline { 5 - 6 } Nurse & Injected activity $(\mathrm{MBq})$ & Patients handled $(n)$ & Time per patient $(\mathrm{min})$ & Right hand & Left hand \\
\hline 1 & $291 \pm 42$ & 5 & $22.23 \pm 1.23$ & $5.5 \pm 0.83$ & $3.8 \pm 0.74$ \\
2 & $284 \pm 46$ & 4 & $23.67 \pm 1.02$ & $6.4 \pm 1.33$ & $4.6 \pm 0.71$
\end{tabular}

*Total for 7 samples.

Data are mean \pm SD. 
TABLE 5

Dose Rates at Various Time Points and Distances from Anterior Chest of Patients

\begin{tabular}{|c|c|c|c|c|c|c|}
\hline \multirow[b]{2}{*}{ Time after injection (h) } & \multirow[b]{2}{*}{ Distance (m) } & \multicolumn{3}{|c|}{$\begin{array}{l}\text { Measured mean dose rate }(\mu \mathrm{Sv} / \mathrm{h}) \text { from } \\
\text { patient after mean injected activity of } \\
288 \mathrm{MBq}(7.8 \mathrm{mCi})(n=12)\end{array}$} & \multicolumn{2}{|c|}{$\begin{array}{l}\text { Calculated dose rate/MBq } \\
\text { injected }(\mu \mathrm{Sv} / \mathrm{MBq} \cdot \mathrm{h})\end{array}$} \\
\hline & & Net & Gross & Range & Mean & Range \\
\hline \multirow[t]{2}{*}{0} & 0.1 & 82.58 & 83.44 & $60-115$ & 0.286 & $0.19-0.36$ \\
\hline & 1 & 6.85 & 7.63 & $5.51-7.67$ & 0.023 & $0.02-0.03$ \\
\hline \multirow[t]{2}{*}{1} & 0.1 & 17.14 & 18.25 & $5.40-32$ & 0.060 & $0.02-0.11$ \\
\hline & 1 & 0.78 & 1.61 & $0.55-1.17$ & 0.003 & $0.001-0.004$ \\
\hline \multirow[t]{2}{*}{2} & 0.1 & 4.43 & 5.25 & $1.20-6.11$ & 0.015 & $0.004-0.019$ \\
\hline & 1 & 0.57 & 1.09 & $0.46-0.68$ & 0.002 & $0.001-0.003$ \\
\hline \multirow[t]{2}{*}{4} & 0.1 & 1.23 & 2.05 & $0.55-2.10$ & 0.004 & $0.001-0.006$ \\
\hline & 1 & 0.22 & 0.93 & $0.21-0.32$ & 0.0006 & $0.0003-0.0007$ \\
\hline
\end{tabular}

The radiopharmacists received a higher dose to their hands (though well within acceptable limits) during elution and synthesis, as both the amount of activity handled and the time involved are maximized during these procedures. The radiation workers who injected the activity had a much lower exposure than the radiopharmacists because the time involved was much less. The staff was educated to practice the cardinal principles of time, distance, and shielding, and techniques were enforced to keep the exposure as low as reasonably achievable. The radiopharmacists were advised to use long tongs or forceps to handle the radioactivity vials and syringes so as to lessen exposure of the hands. The workers who injected the activity minimized their time with the patient after the injection was given; instead, they spent time beforehand thoroughly explaining the procedure to the patient, answering any questions, and ensuring patient comfort. Time spent with the patient on completion of the scan was also minimized.

\section{CONCLUSION}

This study monitored the radiation exposure to personnel during the use of ${ }^{213} \mathrm{Bi}$-radiopharmaceuticals. External radiation doses to workers were far below the limit prescribed by the regulatory authority $(20 \mathrm{mSv} / \mathrm{y})$. The dose rates from patients administered ${ }^{213} \mathrm{Bi}$-radiopharmaceuticals were low enough to allow treatment in a convenient ambulatory setting. This study was significant because, to our knowledge, there have been no other studies monitoring the staff involved with ${ }^{213} \mathrm{Bi} \alpha$-therapy.

\section{DISCLOSURE}

No potential conflict of interest relevant to this article was reported.

\section{REFERENCES}

1. Mulford DA, Scheinberg DA, Jurcic JG. The promise of targeted $\alpha$-particle therapy. J Nucl Med. 2005;46(suppl):199S-204S.

2. Pagel JM, Kenoyer AL, Back T, et al. Anti-CD45 pretargeted radioimmunotherapy using bismuth-213: high rates of complete remission and long-term survival in a mouse myeloid leukemia xenograft model. Blood. 2011;118:703-711.

3. Zielinska B, Apostolidis C, Bruchertseifer F, Morgenstern A. An improved method for the production of Ac-225/Bi-213 from Th-229 for targeted alpha therapy. Solvent Extr Ion Exch. 2007;25:339-349.

4. Chan HS, Blois E, Morgenstern A, et al. In vitro comparison of ${ }^{213} \mathrm{Bi}-$ and ${ }^{177} \mathrm{Lu}$ radiation for peptide receptor radionuclide therapy. PLoS One. 2017;12:e181473.

5. Boll RA, Malkemus D, Mirzadeh S. Production of actinium-225 for alpha particle mediated radioimmunotherapy. Appl Radiat Isot. 2005;62:667-679.

6. Kratochwil C, Giesel FL, Bruchertseifer F, et al. ${ }^{213}$ Bi-DOTATOC receptortargeted alpha-radionuclide therapy induces remission in neuroendocrine tumours refractory to beta radiation: a first-in-human experience. Eur J Nucl Med Mol Imaging. 2014;41:2106-2119.

7. International Basic Safety Standards for Protection Against Ionizing Radiation and for the Safety of Radiation Sources: IAEA Safety Series No. 115. Vienna, Austria: IAEA; 1996.

8. The 2007 recommendations of the International Commission on Radiological Protection: ICRP publication 103. Ann ICRP. 2007;37:1-332.

9. Dauer LT, Williamson MJ, Humm J, et al. Radiation safety considerations for the use of ${ }^{223} \mathrm{RaCl}_{2} \mathrm{DE}$ in men with castration-resistant prostate cancer. Health Phys. 2014; 106:494-504.

10. Smith DS, Stabin MG. Exposure rate constants and lead shielding values for over 1,100 radionuclides. Health Phys. 2012;102:271-291.

11. Bayram T, Yilmaz AH, Demir M, Sonmez B. Radiation dose to technologists per nuclear medicine examination and estimation of annual dose. J Nucl Med Technol. 2011;39:55-59.

12. Dwivedi DK, Snehlata, Dwivedi AK, et al. Radiation exposure to nuclear medicine personnel handling positron emitters from Ge-68/Ga-68 generator. Indian J Nucl Med. 2011;26:86-90.

13. Roberts FO, Gunawardana DH, Pathmaraj K. Radiation dose to PET technologists and strategies to lower occupational exposure. J Nucl Med Technol. 2005;33:44-47.

14. Donmoon T, Chamroonrat W, Tuntawiroon M. Radiation exposure to nuclear medicine staffs during ${ }^{18} \mathrm{~F}$-FDG PET/CT procedures at Ramathibodi Hospital. J Phys Conf Ser. 2016;694:012061.

15. Andreeff M, Wunderlich G, Behge K, Schönmuth T, Kotzerke J. Beta-radiation exposure with ${ }^{188}$ Re-labelled pharmaceuticals [in German]. Nuklearmedizin. 2005; 44:94-98.

16. Arora G, Mishra R, Kumar P, et al. Estimation of whole body radiation exposure to nuclear medicine personnel during synthesis of ${ }^{177}$ lutetium-labeled radiopharmaceuticals. Indian J Nucl Med. 2017;32:89-92. 